\title{
Epileptologists probe vagus nerve stimulation in children with refractory epilepsy: a promise against sudden unexpected death in epilepsy
}

\author{
Epileptologistas indicam a estimulação do nervo vago em crianças com epilepsia \\ refratária: uma promessa contra a morte súbita em epilepsia
}

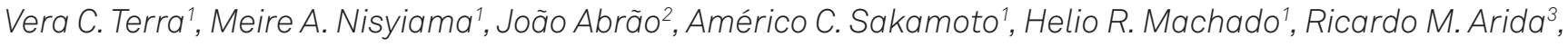
Esper A. Cavalheiro 4 , Fulvio Alexandre Scorza

\begin{abstract}
It is clear that sudden unexpected death in epilepsy (SUDEP) is mainly a problem for people with refractory epilepsy, but our understanding of the best way to its prevention is still incomplete. Although the pharmacological treatments available for epilepsies have expanded, some antiepileptic drugs are still limited in clinical efficacy. In the present paper, we described an experience with vagus nerve stimulation (VNS) treatment by opening space and providing the opportunity to implement effective preventative maps to reduce the incidence of SUDEP in children and adolescents with refractory epilepsy.
\end{abstract}

Key words: epilepsy, vagus nerve stimulation, SUDEP.

RESUMO

Está claro que a morte súbita e inesperada em epilepsias (SUDEP) é principalmente um problema para as pessoas com epilepsia refratária, mas o entendimento para estabelecer medidas preventivas ainda está incompleto. Embora os tratamentos farmacológicos disponíveis para epilepsias tenham sido expandidos, algumas drogas antiepilépticas ainda são limitadas em termos de eficácia clínica. No presente trabalho, foi descrita uma experiência com a estimulação do nervo vago (VNS), abrindo espaço e fornecendo a oportunidade de implementar eficazes mapas preventivoss para reduzir a incidência da SUDEP em crianças e adolescentes com epilepsia refratária.

Palavras-Chave: epilepsia, estimulação do nervo vago, SUDEP.

Worldwide, epilepsy is considered the most common serious neurological condition that knows no geographic, social, or racial boundaries, occurring in men and women and affecting people of all ages, though it affects more frequently young people in the first two decades of life and those over the age of $60^{1,2}$. In a more specific way, a major proportion of people with epilepsy falls in the pediatric group (18 years-old or less), and approximately $25 \%$ of those patients have medically intractable epilepsy ${ }^{3}$. Furthermore, only 10 to $20 \%$ of the children with epilepsy, who remain presenting active epilepsy in adulthood, will have spontaneous seizure remission, suggesting that early attempts to control epilepsy should be pursuit ${ }^{4-6}$. Often, epilepsy is still seen as a benign condition in which individuals only have seizures. Unfortunately, the story is not as simple as it seems. Epilepsy is a malignant condition that has a high rate of premature death compared with the general population ${ }^{7-9}$.

Most of the excess death is due to the underlying disease causing epilepsy, however some is epilepsy-related, including trauma, suicide, aspiration pneumonia, status epilepticus, mostly due to sudden unexpected death in epilepsy (SUDEP), which is a leading cause of mortality in people with epilepsy ${ }^{7-9}$. From an epidemiological standpoint, results from a US population-based study indicate

\footnotetext{
${ }^{1}$ Centro de Cirurgia de Epilepsia (CIREP), Departamento de Neurociências e Ciências do Comportamento, Faculdade de Medicina de Ribeirão Preto, Universidade de São Paulo, Ribeirão Preto SP, Brazil;

${ }^{2}$ Departamento de Biomecânica, Medicina e Reabilitação do Aparelho Locomotor, Faculdade de Medicina de Ribeirão Preto, Universidade de São Paulo, Ribeirão Preto SP, Brazil;

${ }^{3}$ Departamento de Fisiologia, Escola Paulista de Medicina, Universidade Federal de São Paulo (UNIFESP/EPM), São Paulo SP, Brazil.

${ }_{4}^{4}$ Disciplina de Neurologia Experimental, Escola Paulista de Medicina, Universidade Federal de São Paulo (UNIFESP/EPM), São Paulo SP, Brazil.

Correspondence: Fulvio Alexandre Scorza; Disciplina de Neurologia Experimental; Rua Botucatu 862; 04023-900 São Paulo SP - Brasil; E-mail: scorza.nexp@epm.br Conflict of interest: There is no conflict of interest to declare.

Received 21 March 2012; Received in final form 26 April 2012; Accepted 03 May 2012
} 
that the risk of sudden death in people with epilepsy is estimated to be at least 20 times higher than that of the general population ${ }^{10}$. In general terms, SUDEP is responsible for 7.5 to $17 \%$ of all deaths in people with epilepsy, and it has an incidence among adults between 1:500 and 1:1,000 patient-years ${ }^{11}$. Concerning risk factors, the main currently described are refractoriness of the epileptic condition, presence of convulsive seizures, early onset of epilepsy, antiepileptic medication (polytherapy with antiepileptic drugs), young age, and duration of the seizure disorder ${ }^{9,12,13}$. The causes of SUDEP are still unknown, but researches consistently suggest that the main mechanism for SUDEP is autonomic dysregulation, i.e., cardiac and respiratory abnormalities during and after seizures ${ }^{9,12-14}$. In addition, it is clear that SUDEP is mainly, but not exclusively, a problem for people with uncontrolled epilepsy ${ }^{13}$, but our understanding of the best way to its prevention is still incomplete. Strict evidence still lacks for its effectiveness, but epidemiologic and observational data seem to suggest some measures to minimize the risk of SUDEP, and these include: good seizure control, stress reduction, participation in physical activity and sports (with appropriate professional supervision), dietary management (omega-3 supplementation), night supervision, family members' knowledge of cardiopulmonary resuscitation techniques, and the basics of defibrillator use $\mathrm{e}^{13,15,16}$.

Despite the great scientific advances of SUDEP over the past two decades, most of the information described above was conducted in adults and, unfortunately, we still have little data regarding SUDEP in children ${ }^{17,18}$. According to the excellent review article published recently by Sascha Meyer et al. ${ }^{18}$, epileptic children and adolescents with refractory seizures, early-onset epilepsy, and developmental retardation seem to be at higher risk for SUDEP. Following this line of reasoning, we reviewed the occurrence of SUDEP in children in our epilepsy unit over an eight-year period ${ }^{19}$. Our study evaluated SUDEP incidence in a cohort of children aged between 0 and 18 years-old, who were evaluated in the Clinical Hospital of Ribeirão Preto in 2000 and followed-up until June, in 2008. Briefly, from the 835 patients evaluated, 12 had suffered SUDEP and nearly all of the SUDEP cases in our children were related to chronic uncontrolled epilepsy (daily $-50.0 \%$, two to four/weeks - 41.7\%, monthly - 8.3\%). Furthermore, the high frequency of generalized tonic-clonic seizures and polytherapy with antiepileptic drugs may also be highlighted as risk factors in our study ${ }^{19}$.

By assessing the information set out so far and considering that although the availability of pharmacological and surgical treatment for epilepsy has expanded, antiepileptic drugs and some resective procedures are still limited in clinic efficacy. Thus, the desire to find alternative treatments for untreatable epilepsy has led epileptologists to use therapeutic devices in order to minimize the occurrence of SUDEP. For that, vagus nerve stimulation (VNS) may receive a prominent role in this scenario. It has been established that patients with medically intractable epilepsy, who are not candidates for epilepsy surgery, could benefit from neurostimulation ${ }^{20}$.

Hence, VNS therapy is the only neurostimulation modality approved by the Food and Drug Administration (FDA). It has been shown to be efficacious and as well tolerated in children and adolescents as in adults ${ }^{20}$. Furthermore, it has been shown to be a cost-effective treatment, reducing direct medical costs, and improving health-related quality of life measures $^{20}$. In a similar way, we have the same positive experience with VNS therapy.

In brief, we analyzed 36 patients up to 18 years-old, with medically intractable epilepsy submitted to VNS implantation. In these patients, a reduction of at least $50 \%$ of seizures was achieved in $61.3 \%$ of the cases and $12.1 \%$ of the individuals had more than $90 \%$ of seizure frequency reduction. Furthermore, $47.2 \%$ of the patients needed frequently hospitalization before VNS implantation and, in follow-up, this number dropped out to $8.3 \%$. In sum, we concluded that VNS demonstrated to be effective in reducing seizure frequency and reducing the need of hospitalization in children with some refractory epilepsies, and it should be considered as an option even in countries with limited resources.

On the whole, it seems reasonable to assume that the risk of sudden death is clearly increased in the epilepsy population, and SUDEP is the most important direct epilepsy-related cause of death. The establishment of SUDEP mechanisms is important for starting preventative measures for SUDEP and for striving to the best control of seizures. Finally, these VNS results open space and provide us the opportunity of implementing effective preventative maps to reduce SUDEP incidence in children and adolescents with refractory epilepsy.

\section{References}

1. Sander JW. The epidemiology of epilepsy revisited. Curr Opin Neurol 2003;16:165-170.

2. de Boer HM, Mula M, Sander JW. The global burden and stigma of epilepsy. Epilepsy Behav 2008;12:540-546.
3. Snead III OC. Surgical treatment of medically refractory epilepsy in childhood. Brain Dev 2001;23:199-207.

4. Aicardi J. Risk factors in recurrent seizures and in mental retardation. Rev Neurol 1997;25:754-756. 
5. Farmer JP, Montes JL, Freeman CR, Meagher-Villemure K, Bond MC, O'Gorman AM. Brainstem Gliomas. A 10-year institutional review. Pediatr Neurosurg 2001;34:206-214.

6. Sillanpää M. Epilepsy in children: prevalence, disability, and handicap. Epilepsia 1992;33:444-449.

7. Nashef L, Ryvlin P. Sudden unexpected death in epilepsy (SUDEP): update and reflections. Neurol Clin 2009;27:1063-1074.

8. Duncan JS, Sander JW, Sisodiya SM, Walker MC. Adult epilepsy. Lancet 2006;367:1087-1100.

9. Nei M, Hays R. Sudden unexpected death in epilepsy. Curr Neurol Neurosci Rep 2010;10:319-326.

10. Ficker DM, So EL, Shen WK, et al. Population-based study of the incidence of sudden unexplained death in epilepsy. Neurology 1998,51:1270-1274.

11. Schuele SU, Widdess-Walsh P, Bermeo A, Lüders HO. Sudden unexplained death in epilepsy: the role of the heart. Cleve Clin J Med 2007;74:S121-127.

12. Surges R, Thijs RD, Tan HL, Sander JW. Sudden unexpected death in epilepsy: risk factors and potential pathomechanisms. Nat Rev Neurol 2009;5:492-504.

13. Tomson T, Nashef L, Ryvlin P. Sudden unexpected death in epilepsy: current knowledge and future directions. Lancet Neurol 2008;7:1021-1031.
14. Stollberger C, Finsterer J. Cardiorespiratory findings in sudden unexplained/unexpected death in epilepsy (SUDEP). Epilepsy Res 2004;59:51-60.

15. ScorzaFA, ColugnatiDB, PansaniAP, SonodaEY,Arida RM, Cavalheiro EA. Preventing tomorrow's sudden cardiac death in epilepsy today: what should physicians know about this? Clinics 2008; 63:389-394.

16. Scorza FA, Arida RM, Terra VC, Cavalheiro EA. What can be done to reduce the risk of SUDEP? Epilepsy Behav 2010;18:137-138

17. Weber P, Bubl R, Blauenstein U, Tillmann BU, Lütschg J. Sudden unexplained death in children with epilepsy: a cohort study with an eighteen-year follow-up. Acta Paediatr 2005;94:564-567.

18. Meyer S, Shamdeen MG, Gottschling S, Strittmatter M, Gortner L. Sudden unexpected death in epilepsy in children. J Paediatr Child Health 2011;47:326-331.

19. Terra VC, Scorza FA, Sakamoto AC, et al. Does sudden unexpected death in children with epilepsy occur more frequently in those with high seizure frequency? Arq Neuropsiquiatr 2009;67:1001-1002.

20. Kotagal P. Neurostimulation: vagus nerve stimulation and beyond. Semin Pediatr Neurol 2011;18:186-194. 